\title{
Reflections on Editing the Journal: Current Status and Future Directions
}

\section{Brooke Fisher Liu' ${ }^{1}$ () and Jeannette lannacone ${ }^{1}$ ()}

1. Department of Communication, University of Maryland College Park, College Park, MD, USA

\begin{abstract}
With the ongoing COVID-19 pandemic, we are facing another watershed moment for our field. There truly could not be a better time to be editing an open-access journal for the international community of risk and crisis communication scholars and practitioners. In this essay, we provide an update on the Journal's status in terms of acceptance rates, global perspective, and readership rates.
\end{abstract}

KEYWORDS: risk, crisis, communication

The September 11 terrorist attacks first drew my attention to the importance of risk and crisis communication research, and my interest was crystallized while collecting my dissertation data on government crisis communication for special needs populations during Hurricane Katrina. With the ongoing COVID-19 pandemic, we are facing another watershed moment for our field. There truly could not be a better time to be editing an open-access journal for the international community of risk and crisis communication scholars and practitioners. As I end my 2-year editorial term, I am proud of what we have accomplished and am eager for the Journal's continued growth. In this essay, my editorial assistant and I provide an update on the Journal's status in terms of acceptance rates, global perspective, and readership rates.

CONTACTS Brooke Fisher Liu (D) - E-mail: bfliu@umd.edu • Department of Communication, University of Maryland College Park, 4300 Chapel Dr., College Park, MD 20740, USA

Jeannette lannacone (D) - E-mail: jviens@umd.edu • Department of Communication, University of Maryland College Park, 4300 Chapel Dr., College Park, MD 20740, USA 


\section{Acceptance Rate and Review Timeframe}

During the past 2 years, the Journal has witnessed growth in submissions as well as continued to establish itself as a premiere outlet for risk and crisis communication scholarship. From March 2018 to March 2020, 88 manuscripts were submitted. Thirty manuscripts were accepted, whereas 39 were rejected. Fourteen manuscripts were withdrawn either because of poor fit with the Journal or the authors declined to revise and resubmit their research. As such, the Journal had a $34 \%$ acceptance rate during these 2 years. As of March 31, 2020, five articles submitted were still under review. Of the manuscripts that received "revise and resubmit" decisions, $63 \%$ were then accepted to the Journal and $27 \%$ were rejected over the past 2 years. At the time we wrote this essay, $10 \%$ of manuscripts that received revise and resubmit decisions had not yet been resubmitted.

The editorial team has taken strides to reduce turnaround time for manuscripts submitted during the past 2 years. The mean and medium review times are less than 60 days. We appreciate the Editorial Board's many contributions to the Journal, most especially their timely and constructive reviews.

\section{Global Perspective}

The Journal is dedicated to human and mediated communication issues associated with crises, risks, and emergencies around the world. Our emphasis on the international is reflected in our global editorial board and represented by the authors and articles we publish. In the past 2 years, author institutions of accepted articles have come from Australia, Belgium, the Netherlands, Sweden, the United Kingdom, and the United States. Furthermore, articles have examined the communication surrounding crises and risks around the world. Scholars have analyzed cases and sites in Australia, Cyprus, England, Estonia, Finland, France, Germany, Greece, Japan, Puerto Rico, South Korea, and the United States. Beyond representing authors and contexts on a global scale, articles published in the Journal have been downloaded around the world. The top 10 countries from which articles are downloaded are ranked as follows: 

1. United States
2. United Kingdom
3. Netherlands
4. Australia
5. Malaysia
6. Canada
7. India
8. Germany
9. Indonesia
10. France

In author institutions, article sites, and dissemination of articles, the Journal truly encapsulates its international mission, helping to share knowledge and research on crises and risks at the global level. We encourage additional submissions from researchers from around the world.

\section{Growing Readership}

The dissemination of the Journal and its articles has continued to grow. In the past 2 years, there have been 12,058 downloads. The majority of downloads come from educational institutions (74\%) followed by commercial institutions (18\%). Government institutions (3\%) and other/nondescript organizations (5\%) make up the remaining percentage of downloads. The top five downloaded articles are Benoit (2018) at 5,152 downloads, Alsulaiman and Rentner (2018) at 501 downloads, Novak et al. (2019) at 460 downloads, Sellnow et al. (2019) at 453 downloads, and SellnowRichmond et al. (2018) at 428 downloads. As an open access journal, we are fundamentally driven by the purpose of spreading crisis and risk communication knowledge around the globe.

\section{Future Directions}

In this essay, we have demonstrated the growing stature and reach of the Journal. The Journal also remains nimble and responsive to the defining crises of our time, including the special call for research on COVID-19. There are opportunities for continued growth in terms of publishing more research from diverse locations around the globe and reaching more nonacademic institutions. As the 
world's attention remains on the COVID-19 pandemic, we must rise to the challenge of disseminating research that can support responses to this crisis and the ones that we will face in the future. It has been an honor to edit this Journal, and we thank the entire editorial team for their service.

\section{ORCID}

Brooke Fisher Liu (i) https://orcid.org/oooo-0003-1985-8050 Jeannette Iannacone () https://orcid.org/000o-0002-0245-6592

\section{References}

Alsulaiman, S. A., \& Rentner, T. L. (2018). The health belief model and preventive measures: A study of the ministry of health campaign on coronavirus in Saudi Arabia. Journal of International Crisis and Risk Communication Research, 1(1), 27-56. https:// doi.org/10.30658/jicrcr.1.1.3

Benoit, W. L. (2018). Crisis and image repair at United Airlines: Fly the unfriendly skies. Journal of International Crisis and Risk Communication Research, 1(1), 11-26. https://doi. org/10.30658/jicrcr.1.1.2

Novak, J. M., Day, A. M., Sopory, P., Wilkins, L., Padgett, D. R., Eckert, S., Noyes, J., Allen, T., Alexander, N., Vanderford, M., \& Gamhewage, G. (2019). Engaging communities in emergency risk and crisis communication: A systematic review and evidence synthesis. Journal of International Crisis and Risk Communication Research, 2(1), 61-96. https://doi. org/10.30658/jicrcr.2.1.4

Sellnow, T. L., Parrish, A., \& Semenas, L. (2019). From hoax as crisis to crisis as hoax: Fake news and information disorder as disruptions to the discourse of renewal. Journal of International Crisis and Risk Communication Research, 2(1), 121-142. https://doi.org/10.30658/jicrcr.2.1.6

Sellnow-Richmond, D. D., George, A. M., \& Sellnow D. D. (2018). An IDEA model analysis of instructional risk communication in the time of Ebola. Journal of International Crisis and Risk Communication Research, 1(1), 135-166. https://doi. org/10.30658/jicrcr.1.1.7 